九州大学学術情報リポジトリ

Kyushu University Institutional Repository

\title{
Design and Performance Analysis of a Seed Metering Device for a Buckwheat Seeder Adopting Discrete Element Analysis
}

\section{LI, Mingsheng}

College of Engineering and Technology, Southwest University

\section{MITSUOKA, Muneshi}

Laboratory of Agricultural Machinery and Production Systems Design, Division of Bioproduction Environmental Sciences, Department of Agro-environmental Sciences, Faculty of Agriculture, Kyushu University

\section{INOUE, E i j i}

Laboratory of Agricultural Machinery and Production Systems Design, Division of Bioproduction Environmental Sciences, Department of Agro-environmental Sciences, Faculty of Agriculture, Kyushu University

YE, Jin

College of Engineering and Technology, Southwest University

他

https://doi.org/10.5109/2558904

出版情報: 九州大学大学院農学研究院紀要. 65 (1)，pp.123-129，2020-02. Faculty of Agriculture， Kyushu University

バージョン :

権利関係 : 


\title{
Design and Performance Analysis of a Seed Metering Device for a Buckwheat Seeder Adopting Discrete Element Analysis
}

\author{
Mingsheng LI ${ }^{1 *}$, Muneshi MITSUOKA², Eiji INOUE², Jin YE ${ }^{1}$, Jian LIU' ${ }^{1}$, Shi YANG ${ }^{1}$, Baigong ZENG ${ }^{1}$, \\ Xiaoxia SONG ${ }^{3}$, Takashi OKAYASU ${ }^{2}$ and Yasumaru HIRAI ${ }^{2}$
}

\author{
Laboratory of Agricultural Machinery and Production Systems Design, Division of Bioproduction \\ Environmental Sciences, Department of Agro-environmental Sciences, Faculty of Agriculture, \\ Kyushu University, Fukuoka 819-0395, Japan \\ (Received October 30, 2019 and accepted November 14, 2019)
}

\begin{abstract}
An external groove wheel type of buckwheat seed metering device is designed for the buckwheat seeder. We establish a discrete element analysis model of the seed metering device and buckwheat seed using physical and mechanical parameters of buckwheat seeds experimentally measured and calculated. The effects of the rotational speed, groove radius and groove number on the seed metering rate are analyzed in an L4 (23) mixed orthogonal test and supplementary test. The simulation results show that the seed metering device performs best when the groove radius is $3 \mathrm{~mm}$, there are 20 grooves, and the rotational speed is $55.67 \mathrm{r} / \mathrm{min}$. The single-factor test results of the rotational speed of the buckwheat metering device show that the relationship between the metering rate and rotational speed is approximately linear. The metering rate of the metering device reaches a target value of $3.79 \mathrm{~g} / \mathrm{s}$ at a rotational speed of $47.85 \mathrm{r} /$ $\min$
\end{abstract}

Key words: Buckwheat, Seed metering device, Discrete element analysis, Orthogonal tests

\section{INTRODUCTION}

Buckwheat has been planted in China for thousands of years and an area of 1.3 million hectares is presently planted perennially. Buckwheat is mainly planted in alpine mountainous areas, where areas of farmland are small and scattered and the degree of mechanized sowing is low.

Buckwheat seeders are mostly modified from other grain seeders, such as wheat seeders and corn seeders. However, the physical and mechanical properties of buckwheat seeds are different from those of wheat and maize. Modified buckwheat seeders therefore have a poor seeding effect. The main reason is that the seed metering device of the seeder has not been specially designed for buckwheat seeds.

There are six types of metering device of the grain seeder: the outer groove wheel type, inner groove wheel type, hobbing gear type, winch type, pendulum rod type and centrifugal type. The outer groove wheel type is the metering device most commonly used for a grain seeder. The seeding rate of this metering device has a linear relationship with the effective working length of the groove wheel, and it is stable and easy to adjust. The outer groove wheel seeder is therefore suited to buckwheat seeding.

College of Engineering and Technology, Southwest University, China

${ }^{2}$ Laboratory of Agricultural Machinery and Production Systems Design, Division of Bioproduction Environmental Sciences, Department of Agro-environmental Sciences, Faculty of Agriculture, Kyushu University, Japan

School of Foreign Languages, Chongqing College of Humanities, Science \&Technology, China

* Corresponding author (E-mail: limingshengSWU@vip.163. com)
The interaction and dynamic relationship between the seed metering device and buckwheat seeds should be considered in the design of a seed metering device. To this end, researchers have adopted analytical methods based on discrete element theory and continuum theory (Li, Z. Q et al., 2011; Shi, L. R et al., 2014; Liu, Y. Q et al., 2016; Byum, J. H et al., 2018). The discrete element method regards the seeds as a set of rigid elements with independent motion, which is consistent with the physical and mechanical properties of the seeds themselves. Therefore, in the study of the interaction between seeds and a seed metering device, analysis adopting discrete element theory is more accurate than that adopting continuous medium theory.

The present paper designs an outer groove wheel type of seed metering device for the buckwheat seeder by studying the physical and mechanical properties of buckwheat seeds. The seed metering process of the device is simulated through discrete element analysis (DEA) and the parameters of the device are optimized according to the simulation results.

\section{MATERIALS AND METHODS}

\section{Physical and mechanical properties of buckwheat} seeds

Size parameters

The most basic physical parameters of buckwheat seeds are the dimensions of the seeds, including the length $L$, width $W$ and height $H$ of the seeds. To obtain these parameters, the length, width and height of 50 randomly selected buckwheat seeds were measured with a Vernier caliper having accuracy of $0.02 \mathrm{~mm}$, and the average length, width and height of buckwheat seeds are calculated. Using the size parameters of buckwheat seeds, the average equivalent diameter $D$ and sphericity 
$\phi$ of buckwheat seeds were calculated as

$$
\begin{aligned}
& \phi=D / L, \\
& D=\sqrt[3]{L W H} .
\end{aligned}
$$

The size parameters of buckwheat seeds obtained by measurement and calculation are given in Table 1.

Table 1. Size parameters of buckwheat seeds

\begin{tabular}{lccccc}
\hline & $\begin{array}{c}\text { Average } \\
\text { length } \\
(\mathrm{mm})\end{array}$ & $\begin{array}{c}\text { Average } \\
\text { width } \\
(\mathrm{mm})\end{array}$ & $\begin{array}{c}\text { Average } \\
\text { height } \\
(\mathrm{mm})\end{array}$ & $\begin{array}{c}\text { Average } \\
\text { equivalent } \\
\text { diameter } \\
(\mathrm{mm})\end{array}$ & $\begin{array}{c}\text { Average } \\
\text { sphericity } \\
(\%)\end{array}$ \\
\hline $\begin{array}{c}\text { Buckwheat } \\
\text { seeds }\end{array}$ & 6.35 & 4.12 & 3.90 & 4.67 & 74 \\
\hline
\end{tabular}

\section{Seed density}

The density of buckwheat seeds is the ratio of the seed mass to seed volume. In this study, the volume of buckwheat seeds was measured through liquid immersion. As shown in Figure 1, a measuring cylinder was first filled with $5 \mathrm{~mL}$ of water and then filled with a mass $m$ (g) of buckwheat seeds weighed using an electronic scale. The volume of the mixture $V(\mathrm{~mL})$ was recorded after the water surface of the cylinder was stable. The density of buckwheat seeds was calculated as

$$
\rho_{\mathrm{k}}=\frac{m}{V-5} .
$$

An average density of buckwheat seeds of $1.083 \mathrm{~g} /$ $\mathrm{mL}$ was obtained for 10 repeated measurements.

\section{Water content}

The buckwheat seeds were dried in an oven. The water content of buckwheat seeds was obtained by calculating the ratio of the reduced weight of the seeds to the weight of the seeds before drying. The average water content of buckwheat seeds was obtained as $12.4 \%$ for five repeated tests.

\section{Static and dynamic friction coefficients}

Referring to relevant work, the static friction coefficient of buckwheat seed was measured using an inclinometer (Sun, J. X. et al., 2018). As shown in Figure 2,

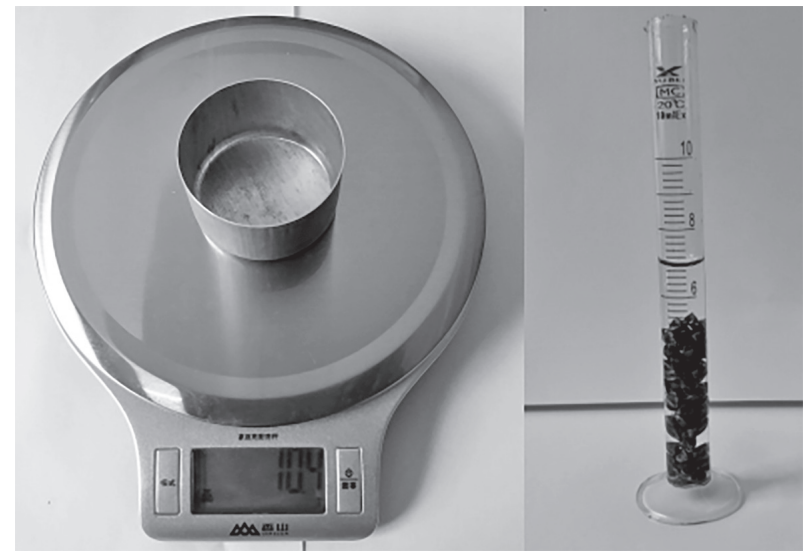

Fig. 1. Density measurement of buckwheat seeds. a buckwheat seed was first placed on the inclinometer and the inclination of the inclinometer was then gradually increased. When the grain began to slide on the inclinometer, the inclination of the inclinometer corresponded to the sliding friction angle. The static friction coefficient of buckwheat seeds was calculated as

$$
\mu_{S}=\tan a,
$$

where $a$ is the inclination of the inclinometer.

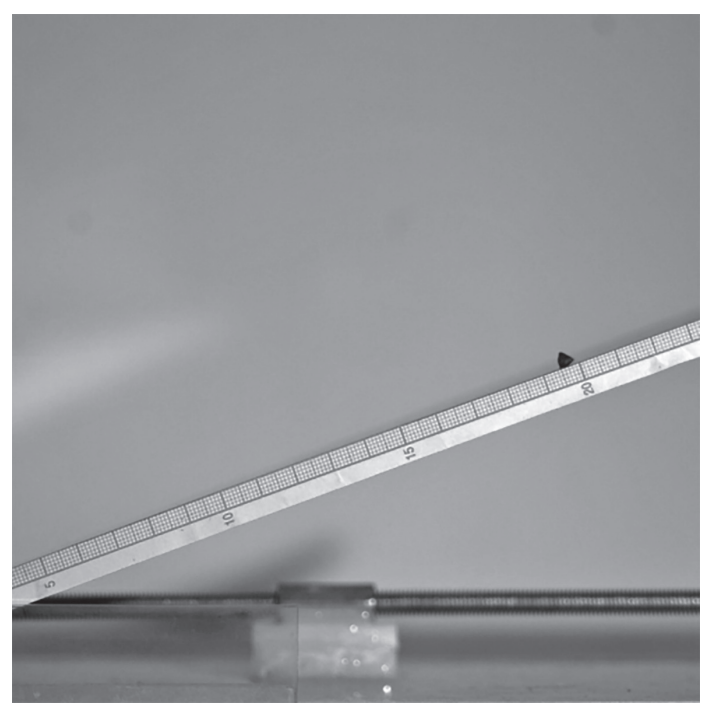

Fig. 2. Inclinometer for measuring the static friction of buckwheat seed.

The inclination of the inclinometer was adjusted to the angle at which buckwheat seeds first slide. According to Newton's first and second laws, the dynamic friction coefficient of buckwheat seeds was calculated as

$$
\mu_{k}=\tan a-\frac{1}{g \cos a} \cdot \frac{S}{\Delta t},
$$

where $S$ is the sliding distance of a seed and $\Delta t$ is the sliding time.

The dynamic and static friction coefficients of buckwheat seeds on different materials are given in Table 2.

Table 2. Dynamic and static friction coefficients of buckwheat seeds on different materials

\begin{tabular}{ccccc}
\hline & Plastic plate & Plexiglass & $\begin{array}{c}\text { Aluminum } \\
\text { plate }\end{array}$ & Seed brush \\
\hline$\mu_{k} / \mu_{S}$ & $0.35 / 0.42$ & $0.58 / 0.73$ & $0.31 / 0.35$ & $0.42 / 0.57$ \\
\hline
\end{tabular}

\section{Coefficient of restitution in collision}

The coefficient of restitution of a buckwheat seed in collision was measured adopting the falling method (Huang, X. M. et al., 2014). A measuring device was designed as shown in Figure 3. Buckwheat seeds fell from a height of $500 \mathrm{~mm}$ to a seed pile, aluminum plate, plexiglass and brush. The collision process of buckwheat seeds was recorded with a high-speed camera, and the rebound height $H$ of buckwheat seeds was read 
from a coordinate board. Using the rebound height $H$, the coefficient of restitution of buckwheat seeds in collision was calculated as

$$
e=\sqrt{\frac{H}{500}} .
$$
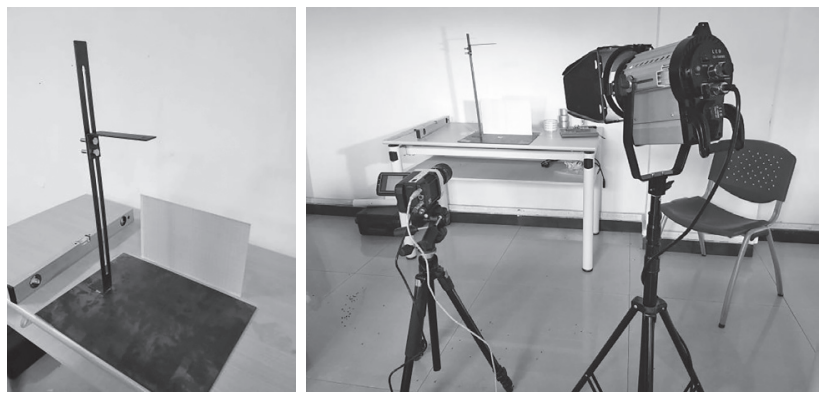

Fig. 3. Device for measuring the coefficient of restitution.

Coefficients of restitution of buckwheat seeds falling on different materials are given in Table 3.

Table 3. Coefficients of restitution e of buckwheat seeds falling on different materials

\begin{tabular}{ccccc}
\hline & \multicolumn{4}{c}{ Collision materials } \\
\cline { 2 - 5 } & $\begin{array}{c}\text { Buckwheat } \\
\text { seed pile }\end{array}$ & $\begin{array}{c}\text { Aluminum } \\
\text { plate }\end{array}$ & Plexiglass & Seed brush \\
\hline $\begin{array}{c}\text { Coefficients } \\
\text { of restitu- } \\
\text { tion } e\end{array}$ & 0.22 & 0.46 & 0.51 & 0.22 \\
\hline
\end{tabular}

\section{Elastic modulus and normal stiffness coefficient}

The elastic moduli of buckwheat seeds in the directions of length, width and height were measured using a WDW3100 compression tester. Fifteen buckwheat seeds were divided into three groups. As shown in Figure 4, the seeds of each group were compressed along length, width and height directions, and the average compressive modulus of buckwheat seeds along these directions was measured. The relationship between buckwheat seed deformation and stress is shown in Figure 5. The slope of the straight line obtained by fitting these data is the normal stiffness coefficient of buckwheat seeds.

The elastic modulus $E$ and normal stiffness coefficient $k_{n 1}$ of buckwheat seeds in the directions of length, width and height are given in Table 4.
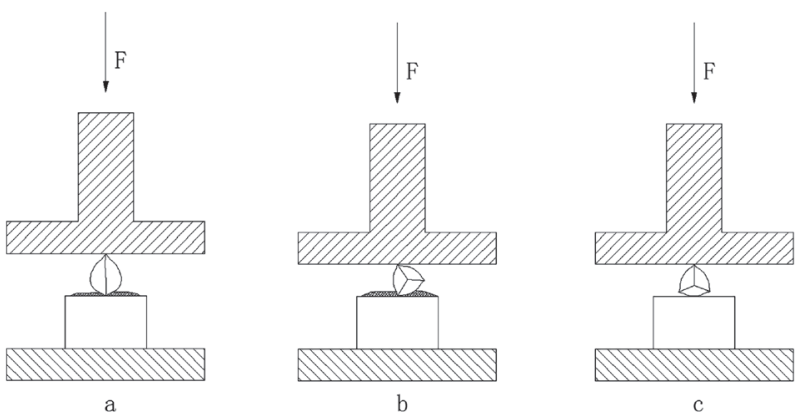

Fig. 4. Sketches of the compression directions.

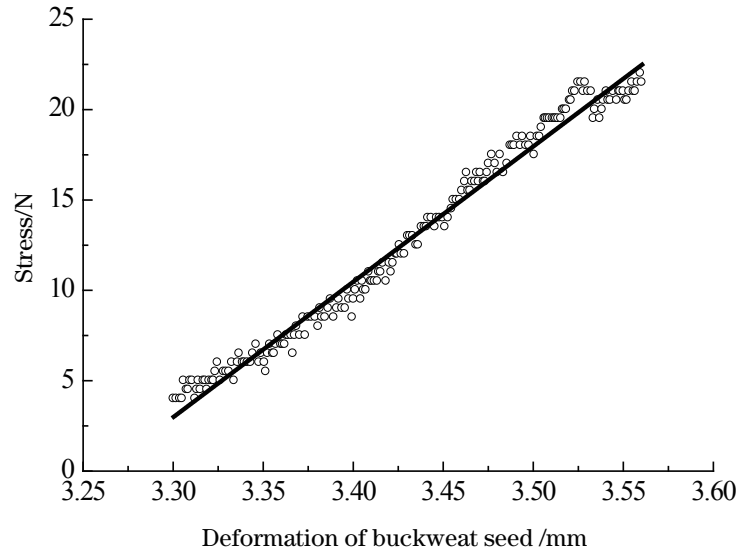

Fig. 5. Linear fitting of the normal stiffness coefficient.

Table 4. Elastic modulus $E$ and normal stiffness coefficient $k_{n 1}$ of buckwheat seeds

\begin{tabular}{cccc}
\hline & $\begin{array}{c}\text { Length } \\
\text { direction }\end{array}$ & $\begin{array}{c}\text { Width } \\
\text { direction }\end{array}$ & $\begin{array}{c}\text { Height } \\
\text { direction }\end{array}$ \\
\hline $\begin{array}{c}\text { Elastic modulus } E(\mathrm{MPa}) \\
\begin{array}{c}\text { Normal stiffness coefficient } \\
k_{n 1}(\mathrm{~N} / \mathrm{mm})\end{array}\end{array}$ & 96.4 & 115.3 & 127.5 \\
\hline
\end{tabular}

\section{Design of the seed metering device}

There are two types of outer groove wheel metering device: the movable groove wheel metering device and the fixed groove wheel metering device. For the movable groove wheel metering device, the groove wheel moves left and right along the seed metering axis in the metering box and the seeding rate can be adjusted by changing the working length of the groove wheel. For the fixed groove wheel metering device, the groove wheel cannot move left or right, and the seeding rate can only be adjusted by changing the speed of the groove wheel. A movable groove wheel metering device is designed in this paper to adjust the seeding rate of buckwheat conveniently.

The designed outer groove wheel buckwheat metering device is shown in Figure 6. The seed metering device mainly comprises a seed brush (labelled 1 in the figure), seed metering wheel (2), seed metering axle (3), seed metering box (4) and seed falling tube connector (5). When the metering device is in operation, buckwheat seeds fill the grooves of the metering wheel under

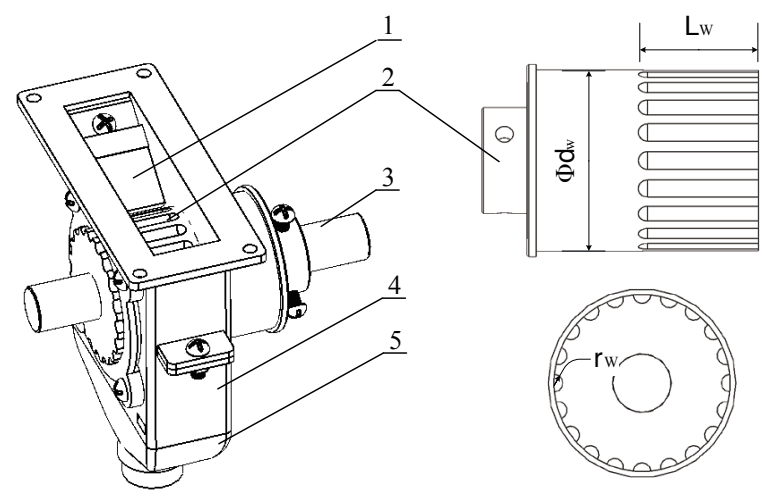

Fig. 6. Structural diagram of the seed metering device. 
the action of the brush and gravity. The seed metering wheel rotates under the drive of the seed metering axis, and the seeds are discharged from the seed metering box to the seed falling tube connector.

The main structural parameters of the buckwheat seed metering device are the diameter $d_{W}$ of the metering wheel, working length $L_{W}$, groove radius $r_{W}$ and groove number $z_{W}$. The effects of physical and mechanical properties of buckwheat seeds should also be considered when the structural parameters of buckwheat seeders are preliminarily determined by referring to other grain metering devices such as those for wheat. Thus, the parameters are preliminarily determined as $d_{W}=$ $60 \mathrm{~mm}, L_{W}=20 \mathrm{~mm}, r_{W}=3 \mathrm{~mm}$, and $z_{W}=20$.

\section{Performance simulation}

To test the performance of the designed buckwheat seed metering device, the working process of the seeder is simulated and analyzed adopting the discrete element method, and the structural parameters of the seeder are optimized according to the simulation results.

\section{Boundary model of seed metering device}

The adoption of the discrete element method to analyze the working process of the outer groove wheel metering device requires the boundary model of the metering device to be established. The boundary model of the metering device is complex and the present study thus adopts a computer-aided design (CAD) model. The CAD model of the metering device is first established and then imported into EDEM software to generate the simulation model. The EDEM post-processing model of the seed metering device is shown in Figure 7.

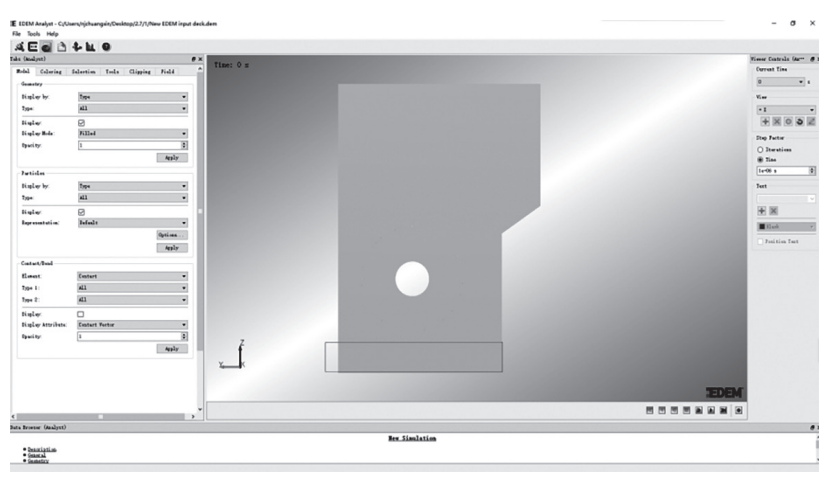

Fig. 7. EDEM post-processing model.

\section{Particle model of buckwheat seed}

One-, two- and three-dimensional methods are often used to simplify material particles and improve the efficiency of analyzing agricultural materials adopting the discrete element method. The model of one-dimensional discrete element method is linear while the models of the two-dimensional discrete element method include circles, ellipses and polygons and the models of the three-dimensional discrete element method include spheres, ellipsoids, hyperspheres, polyhedrons and combined elements.

The complexity and authenticity of the buckwheat seed particle model affect the efficiency and accuracy of the simulation analysis of the buckwheat seed metering device. The combined element model of the threedimensional discrete element method is used in this study to simulate the working process of the buckwheat metering device truly and efficiently. Figure 8 shows the buckwheat seed particle model based on combining elements.

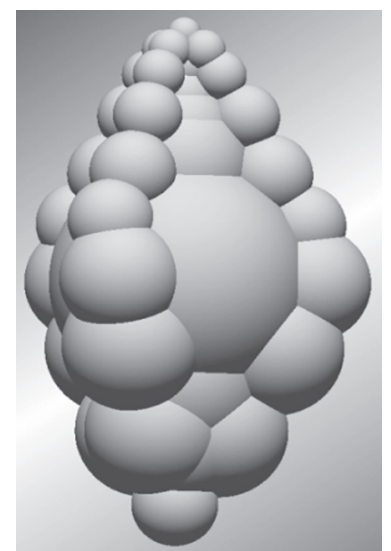

Fig. 8. Particle model of the buckwheat seed based on combined elements.

\section{Mechanics contact model}

DEA usually decomposes contact forces acting between particles and particles and between particles and boundaries into normal contact forces and tangential contact forces and then employs different simplified mechanical models to simulate and analyze these forces. Commonly used simplified mechanical models include the linear spring model, linear cohesion model, HertzMindlin model and hysteretic spring model.

The linear spring model has been widely used in agricultural engineering (Cundall, P. A and Strack, O. D., 1979). As examples, the model was used to study the flow process of maize in silos and to study the screening process of brown rice (Klinker, D. H and Henderson, J. M., 1992; Coetzee, C. J and Els, D. N. J., 2009). Results show that the linear spring mechanics contact model can be reasonably and reliably applied to the DEA of agricultural materials. The present study therefore uses this model in the mechanical analysis of the buckwheat metering device.

\section{Simulation parameters}

Discrete element analysis requires a linear spring model to be established and thus the stiffness and damping coefficients of buckwheat seeds in collision to be obtained.

The normal stiffness coefficient of a buckwheat seed when colliding with a seed metering device is equal to the normal stiffness coefficient of the buckwheat seed itself. Normal stiffness coefficients of buckwheat seeds colliding with each other can be calculated as

$$
k_{n}=\frac{k_{1} k_{2}}{k_{1}+k_{2}}
$$

where $k_{1}$ and $k_{2}$ and are the normal stiffness coefficients 
of colliding buckwheat seeds.

Tangential stiffness is usually considered to be proportional to normal stiffness (Cundall, P. A. and Strack, O. D., 1979). The tangential stiffness coefficients of buckwheat seeds in collision are calculated as

$$
k_{s}=0.8 k_{n} .
$$

The stiffness coefficients of buckwheat seeds colliding in three dimensions are given in Table 5.

Table 5. Stiffness coefficients of buckwheat seeds colliding in three dimensions

\begin{tabular}{|c|c|c|c|c|}
\hline & & $\begin{array}{c}\text { Length } \\
\text { direction }\end{array}$ & $\begin{array}{c}\text { Width } \\
\text { direction }\end{array}$ & $\begin{array}{l}\text { Height } \\
\text { direction }\end{array}$ \\
\hline \multirow[b]{2}{*}{$k_{n}$} & between seeds (N/mm) & 15.1 & 30.7 & 37.5 \\
\hline & $\begin{array}{l}\text { between seed and wall } \\
(\mathrm{N} / \mathrm{mm})\end{array}$ & 30.2 & 61.3 & 74.9 \\
\hline \multirow[b]{2}{*}{$k_{s}$} & between seeds (N/mm) & 12.1 & 24.5 & 30.0 \\
\hline & $\begin{array}{l}\text { between seed and wall } \\
(\mathrm{N} / \mathrm{mm})\end{array}$ & 24.2 & 49.0 & 59.9 \\
\hline
\end{tabular}

The normal damping coefficient is calculated as (Ting, J. M. and Corkum, B. T., 1992)

$$
C_{n}=-2 \ln (e) \sqrt{\frac{k_{n} m_{0}}{\ln ^{2} e+\pi^{2}}},
$$

where $m_{0}$ is the normalized mass.

The tangential damping coefficient is calculated as

$$
C_{s}=-2 \ln (e) \sqrt{\frac{k_{s} m_{0}}{\ln ^{2} e+\pi^{2}}} .
$$

The damping coefficients of buckwheat seeds are as given in Table 6 .

Table 6. Damping coefficients of buckwheat seeds colliding in three dimensions

\begin{tabular}{cccc}
\hline & $\begin{array}{c}\text { Length } \\
\text { direction }\end{array}$ & $\begin{array}{c}\text { Width } \\
\text { direction }\end{array}$ & $\begin{array}{c}\text { Height } \\
\text { direction }\end{array}$ \\
\hline $\begin{array}{l}\text { between seeds (N/ } \\
(\mathrm{m} / \mathrm{s}))\end{array}$ & 0.47 & 0.68 & 0.75 \\
$c_{n} \quad \begin{array}{l}\text { between seed and wall } \\
(\mathrm{N} /(\mathrm{m} / \mathrm{s}))\end{array}$ & 0.67 & 0.96 & 1.06 \\
$\begin{array}{l}\text { between seeds (N/ } \\
(\mathrm{m} / \mathrm{s}))\end{array}$ & 0.42 & 0.60 & 0.67 \\
$c_{s}$ & 0.60 & 0.85 & 0.94 \\
\hline between seed and wall & $\mathrm{N} /(\mathrm{m} / \mathrm{s}))$
\end{tabular}

\section{Orthogonal tests}

Orthogonal tests are designed to simulate the effects of the rotational speed, groove radius and groove number on the seed metering of buckwheat seeds, and the parameters of the seed metering device are optimized according to the simulation results. An L4 $\left(2^{3}\right)$ orthogonal table is used to analyze the performance of the seed metering device. The factors and levels of the orthogonal test are given in Table 7 . According to the operation speed of the buckwheat seeder, the levels of the rotational speed are set at 24.25 and $55.67 \mathrm{r} / \mathrm{min}$. According
Table 7. Factors and levels of the orthogonal test

\begin{tabular}{cccc}
\hline \multirow{2}{*}{ level } & \multicolumn{3}{c}{ Factors } \\
\cline { 2 - 4 } & $\begin{array}{c}\text { Rotational speed } \\
(\mathrm{r} / \mathrm{min})\end{array}$ & $\begin{array}{c}\text { Groove radius } \\
(\mathrm{mm})\end{array}$ & Groove number \\
\hline 1 & 24.25 & 2 & 16 \\
2 & 55.67 & 3 & 20 \\
\hline
\end{tabular}

to the preliminary design parameters of the seed metering device, the levels of the groove radius are set at 2 and $3 \mathrm{~mm}$ while the levels of the groove number are set at 16 and 20.

In the orthogonal test, the target seeding rate is determined to be $3.79 \mathrm{~g} / \mathrm{s}$ according to the requirements of buckwheat planting.

The simulation process is shown in Figure 9. Seed particles are continuously generated by the particle factory and fall into the metering device. Driven by the rotation of the groove wheel of the metering device, the seed particles enter the monitoring area. The seeding rate of the metering device is obtained by counting the number of seed particles entering the monitoring area per unit time.

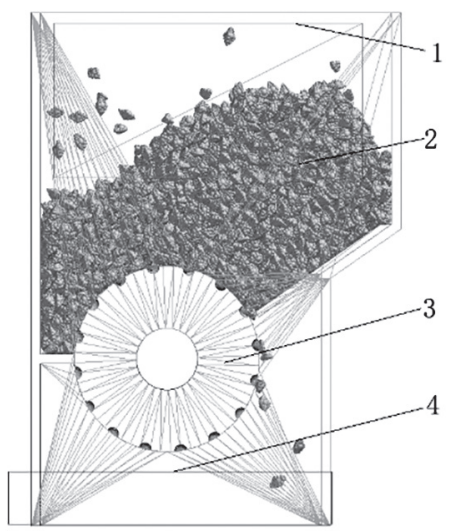

Fig. 9. Simulation model of buckwheat metering device and seeds.

\section{RESULTS AND DISCUSSION}

\section{Analysis of mixed orthogonal test results and parameter optimization of the seed metering device}

The results of mixed orthogonal tests are given in Table $8 . R_{j}$ in the table is the value range of each factor level, which indicates the degree of influence on the metering rate of the metering device. The effect of the factor on the seeding rate increases with the $R_{j}$ value of the factor. Analysis shows that the greatest effect on the seed metering is that of the groove radius, followed by that of the speed of the groove wheel, while the number of grooves has the least effect on seed metering.

In all orthogonal tests, the metering amount of the metering device is less than $3.79 \mathrm{~g} / \mathrm{s}$, and the level of each factor at the maximum metering rate should thus be taken as the optimal level. The optimal project com- 
Table 8. Design scheme and results of mixed orthogonal tests

\begin{tabular}{|c|c|c|c|c|c|}
\hline \multirow[b]{2}{*}{ Test No. } & \multicolumn{3}{|c|}{ Test scheme } & \multirow{2}{*}{$\begin{array}{c}\text { Test result } \\
\begin{array}{c}\text { Seeding rate } \\
(\mathrm{g} / \mathrm{s})\end{array}\end{array}$} & \multirow{2}{*}{$\begin{array}{c}\text { Target } \\
\begin{array}{c}\text { Seeding rate } \\
(\mathrm{g} / \mathrm{s})\end{array}\end{array}$} \\
\hline & $\begin{array}{c}\text { Rotational speed (r/min) } \\
A\end{array}$ & $\begin{array}{l}\text { Groove radius (mm) } \\
B\end{array}$ & $\begin{array}{l}\text { Groove number } \\
\text { C } \\
\end{array}$ & & \\
\hline 1 & 124.25 & 12 & 116 & 0.40 & \multirow{4}{*}{3.79} \\
\hline 2 & 124.25 & 23 & 220 & 1.95 & \\
\hline 3 & 255.67 & 12 & 220 & 0.74 & \\
\hline 4 & 255.67 & 23 & 116 & 3.36 & \\
\hline$K_{1 j}$ & 2.35 & 1.14 & 3.76 & & \\
\hline$K_{2 j}$ & 4.10 & 5.31 & 2.69 & & \\
\hline$k_{1 j}$ & 1.18 & 0.57 & 1.88 & & \\
\hline$k_{2 j}$ & 2.05 & 2.66 & 1.35 & & \\
\hline$R_{j}$ & 0.87 & 2.09 & 0.53 & & \\
\hline Order of factors & & $B>A>C$ & & & \\
\hline Optimal project combination & & $B_{2} A_{2} C_{1}$ & & & \\
\hline
\end{tabular}

bination is thus obtained as $B_{2} A_{2} C_{1}$; i.e., the groove radius is $3 \mathrm{~mm}$, the rotational speed is $55.67 \mathrm{r} / \mathrm{min}$, and the number of grooves is 16 . However, the seeding rate of the metering device under this project combination is still less than the target rate. The reason may be that the interaction between factors $A$ and $B$ has a greater effect on the test results than factor $C$ alone. A supplementary test is thus conducted.

In the supplementary test, the groove radius of the metering device is $3 \mathrm{~mm}$ and the metering rate of the metering device is tested at rotational speeds of 24.25 , 38.17 and $55.67 \mathrm{r} / \mathrm{min}$ for 16 and 20 grooves. The test results are given in Table 9 .

Table 9. Supplementary test results

\begin{tabular}{cccc}
\hline \multirow{2}{*}{ Groove number } & \multicolumn{3}{c}{ Rotational speed (r/min) } \\
\cline { 2 - 4 } & 24.25 & 38.17 & 55.67 \\
\hline 16 & $1.63 \mathrm{~g} / \mathrm{s}$ & $2.27 \mathrm{~g} / \mathrm{s}$ & $3.39 \mathrm{~g} / \mathrm{s}$ \\
20 & $2.02 \mathrm{~g} / \mathrm{s}$ & $2.82 \mathrm{~g} / \mathrm{s}$ & $4.41 \mathrm{~g} / \mathrm{s}$ \\
\hline
\end{tabular}

Table 9 shows that the seeding rate of the seed metering device with 20 grooves is always greater than that of the seed metering device with 16 grooves. Therefore, the exactly optimal project combination is $B_{2} A_{2} C_{2}$; i.e., the groove radius is $3 \mathrm{~mm}$, the rotational speed is $55.67 \mathrm{r} / \mathrm{min}$, and the groove number is 20 .

\section{Single-factor test results and analysis of the seed metering device}

To analyze the effect of the rotational speed of the buckwheat metering device on seed metering and to test whether the project combination $B_{2} A_{2} C_{2}$ meets the requirements of seed metering, the levels of the rotational speed of the seed metering device are divided into smaller gradients for a simulation test, and the relationship between the rotational speed of the seed metering device and the seed metering rate is obtained as shown in Figure 10.

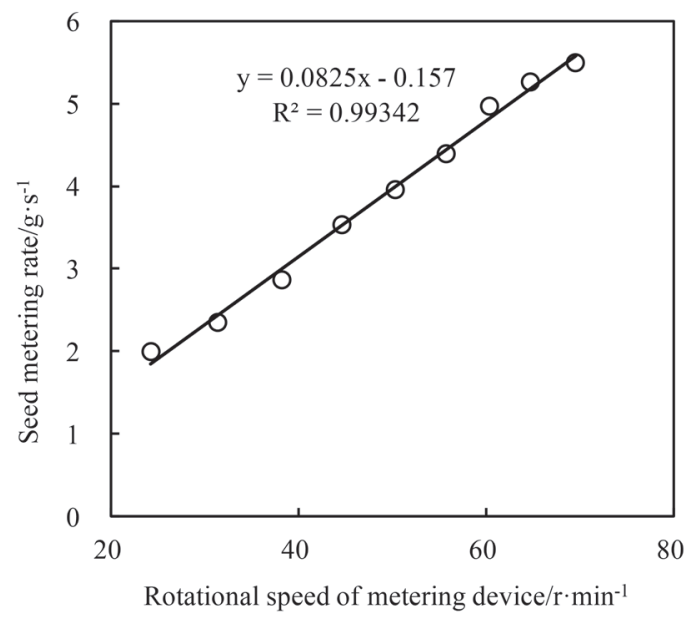

Fig. 10. Relationship between the rotational speed of the seed metering device and the seed metering rate.

Figure 10 reveals that the seed metering rate of the metering device has an approximate linear relationship with the rotational speed, and the correlation coefficient $\mathrm{R}$ of linear fitting is greater than 0.99 . The metering rate of the metering device reaches the target value of $3.79 \mathrm{~g} / \mathrm{s}$ at a rotational speed of $47.85 \mathrm{r} / \mathrm{min}$.

\section{CONCLUSIONS}

Physical and mechanical parameters of buckwheat seeds were measured and calculated. The physical parameters include the dimensions of seeds, seed density and water content. Mechanical parameters were the static friction coefficient, dynamic friction coefficient, restitution coefficient in collision, elastic modulus and normal stiffness coefficient.

Using the physical parameters of buckwheat seeds, an outer groove wheel type of seed metering device was designed for the buckwheat seeder. A boundary model of the seed metering device, buckwheat seed combination element particle model and linear spring mechanical 
contact model were established to analyze the performance of the seed metering device and optimize the structural parameters of the device. The working process of the seed metering device was simulated and analyzed using the discrete element method. The stiffness and damping coefficients of buckwheat seeds in collision were calculated using the physical and mechanical parameters of buckwheat seeds for the purpose of DEA.

In simulation, the effects of the rotational speed, groove radius and groove number on the metering rate were analyzed adopting a mixed orthogonal test and supplementary test. The results of the simulation tests gave an optimum combination of structural parameters of the metering device as a groove radius of $3 \mathrm{~mm}$, rotational speed of $55.67 \mathrm{r} / \mathrm{min}$, and 20 grooves. The singlefactor test results of the rotational speed of the buckwheat metering device showed that the relationship between the metering rate and rotational speed was approximately linear. At a rotational speed of $47.85 \mathrm{r} /$ min, the metering rate of the metering device reached the target value of $3.79 \mathrm{~g} / \mathrm{s}$.

\section{AUTHOR CONTRIBUTIONS}

M.S. Li designed the study, analyzed the data and wrote the paper. E. Inoue and M. Mitsuoka designed the study, supervised the work and provided facilities and resources. J. Ye, J. Liu, S. Yang and B. Zeng participated in the design of the study and performed the simulation. $\mathrm{X}$. X. Song edited the English text of a draft of this manuscript. All authors assisted in editing the manuscript and approved the final version.

\section{ACKNOWLEDGEMENTS}

The authors acknowledge financial support from the National Key Research and Development Program of China (No. 2016YFD0701001) and Chinese Scholarship Council.

\section{REFERENCES}

Li, Z. Q., Yu, J. Q. and Zhang, W. L. 2011 Simulation analysis of working process and performance of inside-filling seed metering device by discrete element method. Transactions of the Chinese Society of Agricultural Engineering (Transactions of the CSAE), $\mathbf{2 7}(11): 32-36$

Shi, L. R., Wu, J. M. and Sun, W. 2014 Simulation test for metering process of horizontal disc precision metering device based on discrete element method. Transactions of the Chinese Society of Agricultural Engineering (Transactions of the CSAE), $\mathbf{3 0}(8): 40-48$

Liu, Y. Q., Zhao, M. Q. and Liu, F. 2016 Simulation and optimization of working parameters of air suction metering device based on discrete element. Transactions of the Chinese Society for Agricultural Machinery, 47(7): 65-73

Byum, J. H., Nam, J. S., Choe, J. S. and Inoue, E. 2018 Analysis of the separating performance of a card cleaner for pepper harvester using EDEM software. J. Fac. Agr., Kyushu Univ., $\mathbf{6 3}(2), 347-354$

Sun, J. X., Guo, Y. M., Yang, Z. M., and Cui, Q. L. 2018 Experimental study on biomechanical properties of buckwheat grain and viscoelastic properties of buckwheat powder. Transactions of the Chinese Society of Agricultural Engineering (Transactions of the CSAE), 34(23): 287-298

Huang, X. M., Cha, X. T., Pan, H. B. and Zong, W. Y. 2014 Measurement and analysis of rapeseeds' restitution coefficient in point-to-plate collision model. Transactions of the Chinese Society of Agricultural Engineering (Transactions of the CSAE), 30(24): 22-29

Cundall, P. A., and Strack, O. D. 1979 A discrete numberical model for granular assemblies. Geotechnique, 29: 47-65

Klinker, D. H. and Henderson, J. M. 1992 Flow model development for spherical discrete objects. Transactions of the ASAE, $\mathbf{3 5}(1)$ : 225-233

Coetzee, C. J and Els, D. N. J. 2009 Calibration of discrete element parameters and the modeling of silo discharge and bucket filling. Computers and Electronics in agriculture, $65(2)$ : $198-212$

Ting, J. M. and Corkum, B. T. 1992. A computational laboratory for discrete element geomechanics. Journal of Computing in Civil Engineering. 6(2): 129-146 
